\title{
Enraizamento, tempo e participação na Psicologia Ambiental ${ }^{1}$
}

Gustavo Martineli Massola. Universidade de São Paulo.

Bernardo Parodi Svartman. Universidade de São Paulo.

\section{Resumo}

A noção de enraizamento na Psicologia Ambiental apresenta caráter polissêmico, delimitando um campo de discussão importante nesta área de conhecimento. De maneira geral, as definições enfatizam a importância do passado e da recorrência dos ambientes vividos na constituição da identidade pessoal e coletiva. O objetivo deste trabalho é colaborar com uma definição mais rigorosa deste termo. Para isso, analisa-se seu uso por autores centrais deste campo do conhecimento e procura-se comparar alguns dos sentidos presentes em suas obras. Defende-se que a ênfase no quadro temporal passado e na recorrência dos lugares representa um viés identitário limitador, o que permite propor que o enraizamento implica a participação ativa em uma coletividade, de modo a articular passado, presente e futuro em projetos coletivos significativos para o indivíduo e seu grupo.

Palavras-chave: psicologia ambiental; territorialidade; perspectiva de tempo; participação.

\begin{abstract}
Rootedness, time, and participation in Environmental Psychology. The notion of rootedness in Environmental Psychology presents a polysemic character and can be understood in different ways, which, however, emphasize the importance of the past and the recurrence of the lived environments in the constitution of personal and collective identity. The objective of this work is to collaborate with a more rigorous definition of this term. For this, it analyzes its use by central authors of this field of knowledge and tries to compare the meanings that it presents in their works. It is argued that the emphasis on the past time frame and the recurrence of the environment represents a limiting identity bias, which allows us to propose that rooting implies active participation in a collectivity, in order to articulate past, present and future in collective projects that are significant for the individual and his/ her group.
\end{abstract}

Keywords: environmental psychology; territoriality; time perspective; participation.

\section{Resumen}

Arraigo, tiempo y participación en la Psicología Ambiental. La noción de arraigo en la Psicología Ambiental presenta carácter polisémico y puede ser entendida de formas distintas, que, sin embargo, enfatizan la importancia del pasado y de la recurrencia de los ambientes vividos en la constitución de la identidad personal y colectiva. El objetivo de este trabajo es colaborar con una definición más rigurosa de este término. Para ello, se analiza su uso por autores centrales de este campo del conocimiento y se busca comparar algunos de los sentidos que presenta en sus obras. Se defiende que el énfasis en el marco temporal pasado y en la recurrencia de los lugares representa un sesgo identitario limitador, lo que permite proponer que el arraigo implica la participación activa en una colectividad, de modo a articular pasado, presente y futuro en proyectos colectivos significativos para el individuo y su grupo.

Palabras clave: psicología ambiental; territorialidad; perspectiva de tiempo; participación. 
O objetivo deste trabalho é apresentar algumas características do uso do termo "enraizamento" na literatura em Psicologia Ambiental de forma a contribuir com sua conceituação mais rigorosa. Conquanto sua polissemia torne-o importante para muitas áreas do conhecimento, na Psicologia Ambiental - em que não se nega sua relevância - ele muitas vezes é utilizado apenas de forma marginal, ou de maneira intercambiável com outros termos, frente aos quais sua especificidade não se explicita (Farias, 2017, p. 138). Ainda assim, é possível defender que, para esta área do conhecimento, o esforço de defini-lo pode apresentar relevância teórico-conceitual, tendo em vista sua recente incorporação ao discurso ambientalista no Brasil e a crescente importância teórica e prática que o desenraizamento, como fenômeno social de amplo escopo, tem recebido na literatura científica internacional. Esta tarefa mostra-se importante em um campo no qual, apesar dos inegáveis avanços dos últimos 40 anos, a advertência de Canter e Craik (1981) de que "avanços conceituais são urgentemente necessários para prover um sentido viável de coerência no campo" (p. 7) continua valendo (Lewicka, 2010, p. 208). Para fazê-lo, serão discutidos os usos deste termo na obra de alguns autores eleitos por sua relevância para o campo, especialmente por terem se constituído, ao longo do tempo, referências centrais para seus principais pesquisadores. Buscamos interpretar e representar com o maior rigor possível a teia semântica de citações e conjuntos temáticos presentes em tais trabaIhos, que nos pareceram ressoar a discussão sobre o tema do enraizamento, naquilo que se convencionou denominar de revisão narrativa.

Trabalhos mais recentes que utilizam enraizamento como variável muitas vezes não chegam a definir o construto (e.g., Broad \& Cavanagh, 2011) ou tendem a ressoar as concepções presentes nos clássicos, razão pela qual demos ênfase a estes em nossa discussão. Seguimos o seguinte roteiro: explicitamos inicialmente nosso entendimento de Psicologia Ambiental e as bases epistemológicas que embasam a análise da bibliografia. Nessa tarefa inicial, demos destaque às noções de campo social e de socioambiente. Posteriormente, apresentamos em quatro seções os principais sentidos do termo enraizamento encontrados a partir da revisão narrativa. Na última seção deste artigo apresentaremos algumas possibilidades de sínteses e conclusões a partir desta revisão crítica.

\section{Ambiente, espaço e tempo}

A discussão dos sentidos de enraizamento na Psicologia Ambiental deve privilegiar as questões, os problemas e as buscas apresentados por este campo do conhecimento, sem perder de vista seu sentido em outros contextos teóricos. Será necessário, assim, iniciarmos por uma discussão sobre como entendemos a própria Psicologia Ambiental, área que se caracteriza por uma grande variedade teórico-conceitual. Ao fazê-lo, procuramos seguir de forma rigorosa os princípios da teoria crítica, que permitem pensar que compreender o fenômeno do enraizamento só é possível "se reconhecermos o movimento histórico do [próprio] conceito, que é, ao mesmo tempo, o da coisa" (Horkheimer \& Adorno, 1973, p. 185). Tal reconhecimento implica a admissão da historicidade radical dos objetos do conhecimento, o que leva Horkheimer (1991) a questionar, no âmbito que concerne a presente discussão, a própria separação entre natureza e cultura (Massola, Crochík, \& Svartman, 2016) e afirmar que "mesmo quando se trata da experiência com objetos naturais como tal, sua naturalidade é determinada pelo contraste com o mundo social, e nesta medida dele depende" (Horkheimer, 1991, p. 40). Esses princípios preconizam a atenção aos movimentos históricos dos campos do conhecimento e inspiram-nos a dar destaque ao eixo histórico do tempo, ao caráter de totalidade que marca o sociambiente e à indissociabilidade entre conhecimento e práxis social.

Uma das características distintivas da Psicologia Ambiental, a partir da metade do século XX, foi a de trazer o "espaço físico para o interior do campo psicológico" (Cavalcanti \& Elali, 2011, p. 15). Seu ímpeto inicial pode ser vinculado ao processo de reconstrução das cidades destruídas após a II Guerra Mundial (Canter \& Craik, 1981), que levou arquitetos e urbanistas a reconhecerem não serem mais capazes de compreender o comportamento dos futuros usuários de suas construções e voltarem-se por isso à Psicologia (Melo, 1991), dando origem à área denominada Psicologia da Arquitetura. A orientação predominante deste campo no final da década de 1960 era a aceitação de uma espécie de relação causal entre ambiente e comportamento individual e, em muitos casos, a defesa de um determinismo arquitetônico sobre o comportamento (Philip, 1996). Nas décadas de 1950 e 1960, assim, a nascente área do conhecimento buscava ganhar compreensão sobre as relações entre o comportamento 
humano e as características do ambiente, definidas em sentido físico-espacial (Canter \& Craik, 1981).

Aos poucos, as questões científicas e sociais que vieram à tona entre as décadas de 1960 e 1970, incluindo a preocupação mundial que se expressava no movimento ecológico e ambiental, foram marcando este campo do conhecimento, cujos questionamentos ampliaram-se face àqueles da Psicologia da Arquitetura. Ao mesmo tempo, as tendências teóricas mais deterministas e positivistas (Lipman \& Harris, 1980) passaram a coexistir com aquelas, cada vez mais importantes neste campo, derivadas das obras de pioneiros da Psicologia Social, entre os quais se destaca Kurt Lewin (1973, 1989). Discussões trazidas pelo modelo bioecológico do desenvolvimento humano, especialmente a consideração do entrelaçamento das noções de Processo, Pessoa, Contexto e Tempo (Bronfenbrenner \& Morris, 2006), também delimitaram um importante caminho para o desenvolvimento da área. Alguns trabalhos inspirados por esses autores buscaram desenvolver teorias holísticas e transacionais a respeito da relação entre pessoa e ambiente, defendendo que o ambiente tanto determina a pessoa quanto é por ela determinado, ou, mais precisamente, que ambos constituem uma unidade de análise, não sendo possível separá-los (Altman \& Rogoff, 1991). Sob esta perspectiva, as análises dos ambientes físicos não podem separá-los de seus aspectos simbólicos (Lipman \& Harris, 1980), surgindo uma valorização dos aspectos sociais do ambiente, agora cada vez mais entendido como um socioambiente. Conquanto conviva com muitos outros paradigmas (Gifford, 2014), o pensamento transacional tem desempenhado papel de destaque na Psicologia Ambiental contemporânea e as questões por ele trazidas têm marcado o trabalho dos pesquisadores e profissionais deste campo, mesmo daqueles que não partilham de seus pressupostos.

Esta reformulação na ideia de ambiente trouxe à tona uma discussão profunda sobre o caráter temporal, e não apenas espacial, do socioambiente. Em vez de tratar o tempo como uma dimensão separada, usada para marcar ou localizar o estado de um fenômeno em determinado momento, como em outras abordagens, o pensamento transacional parte do princípio de que a mudança é inerente a esses sistemas (Altman \& Rogoff, 1991, p. 25) e de que os processos temporais devem ser incorporados à própria definição dos eventos. Altman e Rogoff (1991, p. 26) traçam um paralelo entre o pensamento transacional e as modernas teorias de campo da Física do século XX, como a Teoria da Relatividade.
Entretanto, Tassara (2006, p. 222) faz recuar esta mudança e explica que já no século XIX, "o tempo que transforma os objetos começa a consolidar uma dimensão científica", e "delineia-se uma realidade que é modificada pela ação do tempo histórico processual". O problema do tempo, sob variadas perspectivas teóricas, é, enfim, incorporado, apesar de inúmeras dificuldades $^{2}$, ao conjunto de questões da Psicologia Ambiental (Pinheiro, 2013), fazendo, ao lado da ênfase nos aspectos sociais do ambiente, um contraponto à visão físico-espacial predominante nas décadas de 1950 e 1960.

Esta discussão sobre a ontologia do tempo foi acompanhada na Psicologia Ambiental por uma outra, relativa ao tema da perspectiva temporal - uma dimensão psicológica do tempo (Corral-Verdugo, Fraijo-Sing, \& Pinheiro, 2006) que pode ser entendida como um processo "frequentemente não consciente, por meio do qual as pessoas dividem o fluxo contínuo de experiências em molduras de tempo - passado, presente e futuro -, a fim de proporcionar ordem, coerência e significado às suas vidas" (Pinheiro \& Gurgel, 2011, p. 267). Lewin (1989) e Frank (1939) estão entre os primeiros autores a estudarem o futuro imaginado a fim de compreender a motivação e o comportamento humanos. Lewin (1970, p. 120) afirma que o "espaço de vida de um indivíduo, longe de se limitar ao que ele considera a situação presente, inclui o futuro, o presente e também o passado". Tais categorias de tempo são importantes na formação de expectativas, objetivos, contingências e cenários imaginados e podem variar individualmente (Zimbardo \& Boyd, 2008), recaindo preferencialmente em uma das categorias de tempo. A perspectiva temporal se relaciona de maneira complexa com nossa percepção do lugar. Tuan (2013), por exemplo, defende que a passagem do tempo pode fazer mudar nossa percepção sobre o ambiente, ao conceder-nos familiaridade com o entorno e transformar o espaço indiferenciado em lugar significativo (Tuan, 2013, p. 226).

Ao passo que as discussões sobre a ontologia do tempo no socioambiente levaram a críticas aos modelos empiristas de pesquisa (Saegert \& Winkel, 1990), os trabalhos que investigaram o tema da perspectiva temporal comumente a transformaram em uma variável independente e a compararam com diversos fenômenos psicológicos, encontrando correlações relevantes em muitos campos de pesquisa, como o das condutas pró-ambientais (Milfont \& Demarque, 2015). Atualmente, segundo Pinheiro e Gurgel (2011, p. 271), um dos instrumentos mais utilizados na avaliação da 
orientação temporal é o Zimbardo Time Perspective Inventory (Zimbardo \& Boyd, 1999), que se baseia na premissa de que, quando se desenvolve uma tendência a enfatizar uma das molduras temporais em detrimento das outras, esta pode tornar-se um viés disposicional que pode ser conhecido e permite antecipar as reações do indivíduo em situações cotidianas. A ênfase sobre uma das dimensões implica no abuso ou na subutilização de uma ou mais dimensões temporais e é considerada por Zimbardo e Boyd (1999) como um fator psicológico limitante. A partir disso, Zimbardo e Boyd (2008) contrastam este viés com o que eles denominam de perspectiva temporal balanceada, que definem como "um quadro mental idealizado que permite aos indivíduos alterar de maneira flexível seus quadros temporais entre passado, futuro e presente, dependendo de demandas situacionais" (p. 1272). Uma volumosa tradição de pesquisas que procuraram definir os parâmetros deste modelo ideal, estabelecendo os valores ótimos para cada uma das dimensões, seguiu-se a este trabalho. Há aqui, assim, algo de um esforço crítico e não apenas descritivo ou analítico no horizonte destes trabalhos. Este tom de crítica social não deve surpreender, pois já se encontra na origem desta discussão: Lewin (1970) mostra, por exemplo, que a dedicação ao estudo de um passado histórico de milhares de anos foi responsável pela capacidade maior de resistência dos sionistas alemães ao nazismo, quando comparados com o restante dos judeus (Lewin, 1970, p. 140). O estudo da perspectiva temporal trazia implícito, já em sua origem, uma dimensão política.

Para Zimbardo e Boyd (1999, p. 1285), por sua vez, a realização do pleno potencial humano depende do uso adequado da orientação futura, da orientação presente e da orientação passada, a qual "estabelece as raízes na tradição e fundamenta o sentido de identidade pessoal" (p. 1285). Temos aqui, de maneira sintética, uma das formas pelas quais a Psicologia Ambiental aborda o tema do enraizamento: uma relação com o passado e com a tradição que fundamenta o sentido de identidade pessoal. "Um sentido de passado positivo lhe dá raízes. Um passado positivo lhe dá um chão, provê um sentido de continuidade da vida e permite que você se conecte com a família, a tradição e sua herança cultural" (Zimbardo \& Boyd, 2008, itálico dos autores).

\section{Enraizamento e Tempo: o Passado}

O quadro temporal passado aparece nas discussões sobre enraizamento como sustentáculo da identidade pessoal e coletiva. Tuan (2013), por exemplo, pergunta: "O que pode significar o passado para nós? As pessoas olham para trás por várias razões, mas uma é comum a todos: a necessidade de adquirir um sentido do eu e da identidade" (Tuan, 2013, p. 227). O resgate do passado também é visto por Tuan (2013, p. 228) como uma forma de fortalecer os sentidos do eu em situações nas quais eles encontram-se sob ameaça. De maneira semelhante, Terkenli (1995, p. 331) afirma que em situações nas quais há necessidade de assegurar ou definir identidades pessoais ou coletivas, os seres humanos tendem a retornar imageticamente para seus lares.

Se na literatura a ideia de raiz e enraizamento muitas vezes tem um sentido temporal e uma ênfase no passado, é uma das tarefas da Psicologia Ambiental expor o vínculo indissociável entre tempo e espaço na existência objetiva do socioambiente, bem como estudar sua relação intrínseca com a percepção subjetiva do tempo. A percepção do tempo como uma dimensão separada frente ao espaço é algo que pode decorrer de certos modos de vida, especialmente após a modernidade europeia, em que a criação de instrumentos precisos de medição do tempo, como o relógio mecânico, e de instituições que dependem da coordenação de ações ao longo do globo terrestre, fomentou a percepção social de um tempo abstrato (Giddens, 1991). Mas na experiência cotidiana em sociedades não modernas, tal separação não se dá desta forma, de modo que o ambiente objetivamente percebido possui uma estrutura na qual "espaço e tempo coexistem, entremesclam-se e cada um deles é definido de acordo com a experiência pessoal" (Tuan, 2013, p. 161). Assim, uma das tarefas da Psicologia Ambiental deve consistir em buscar as relações entre diferentes perspectivas temporais e os aspectos socioambientais a elas correspondentes, tendo como princípio, na perspectiva aqui adotada, a necessidade de se observar a totalidade desta relação para que seja possível compreender o sentido específico que cada parte do fenômeno desempenha em sua totalidade. Pode ser útil, em termos analíticos, destacar aspectos nos quais a perspectiva temporal passada se relaciona com o estabelecimento e fortalecimento da identidade pessoal e coletiva, mas, se considerarmos que a própria perspectiva temporal não é desvinculada do socioambiente objetivamente dado, a identidade deve relacionar-se também com aspectos espaciais e temporais do socioambiente presente e futuro. Em outras palavras, é o socioambiente como um todo que dá sustentação identitária aos indivíduos 
ou às coletividades, e é nesta relação, por princípio, que devemos encontrar os componentes que permitam compreender porque, sob certas circunstâncias, o passado pode ganhar destaque frente ao presente ou ao futuro.

Além disso, pode-se afirmar também que não apenas na percepção subjetiva pode haver uma ênfase em uma orientação temporal. Como lembram Pinheiro e Gurgel (2011, p. 268), alguns ambientes nos remetem tipicamente ao passado, como os museus, indicando que há aspectos de sua espacialidade que se relacionam de formas definidas com sua temporalidade. Isso pode ser visto na maneira como uma pessoa organiza seus ambientes íntimos, como a sala ou o quarto (Tuan, 2013, p. 229), e na maneira como se constituem as paisagens das distintas sociedades. Alguns povos possuem concepções bastante superficiais sobre a passagem do tempo, o que Tuan (2013, p. 230) relaciona com a quase ausência de objetos culturais muito antigos. Isso não significa que tais concepções surjam automaticamente da existência de tais artefatos. Pelo contrário, apenas no século XVIII consolidou-se na Europa a moderna concepção de história, e importantes monumentos podiam ser tratados anteriormente com enorme indiferença. Trata-se de um processo pelo qual o tempo passou a recobrir esses objetos de valor cultural, numa relação intrínseca entre constituição objetiva da paisagem e sua interpretação cultural. De maneira semelhante aos indivíduos, as buscas identitárias coletivas podem envolver orientações temporais que enfatizam diferencialmente passado, presente ou futuro na constituição do próprio ambiente.

\section{Enraizamento e Espaço: a Casa}

É possível afirmar, ademais, em sentido contrário à ênfase temporal do enraizamento, que esta noção pode implicar imagens essencialmente espaciais, e não temporais. É assim, por exemplo, que Terkenli (1995) o define: "Enraizamento é outro conceito inerentemente geográfico e é central à noção de lar. O sentido central de enraizamento é o de literalmente pertencer a algum lugar" (p. 329, grifos nossos). Mas ao atribuir ao enraizamento uma conotação fortemente espacial, Terkenli (1995) está extraindo da palavra seu sentido mais direto, aquele da planta que se prende a um lugar específico no solo. E ao entender tal noção como central para a ideia de lar, ele conclui: "Lar pode ser definido fundamentalmente como um contexto espacial" (Terkenli, 1995, p. 325). Enraizar-se pode expressar, sob esta perspectiva, uma relação definida com o espaço, mais que com o tempo.

Pode-se argumentar que a ideia de que o enraizamento envolva a recorrência dos espaços habitados (Schellenberg, Lu, Schimmele, \& Hou, 2018) implique também uma ênfase na perspectiva temporal passada. Muitas vezes, esta discussão aparece quando se afirma que a casa é o lugar constituído pela recorrência ou pelo hábito. Esta ideia parece estar presente na maneira como Tuan (2013) refere-se à casa: "Ao final do dia, o escriturário veste seu paletó e se prepara para regressar à casa. A familiaridade é uma característica do passado. O lar fornece uma imagem do passado" (p. 158). Terkenli (1995) também parece ter isso em mente ao afirmar: "Lar, porém, conota não apenas uma condição física ou espacial, mas também condições sociais e habituais. A essência do lar reside no investimento recorrente de sentido em um contexto" (p. 325). Neste sentido, o enraizamento pode ser entendido como fruto quase automático da recorrência dos ambientes vividos, que levaria a uma familiaridade com os lugares habitados, da qual, muitas vezes, o indivíduo não está plenamente consciente. McAndrew (1998), por exemplo, afirma que o enraizamento "resulta de uma longa habitação em uma localidade e pode levar no extremo a um estado irrefletido de ausência de curiosidade sobre o mundo" (p. 411). Esta definição é inspirada em Tuan, que introduziu um longo debate sobre quão consciente ou não-consciente o enraizamento deve ser.

A caracterização feita por Tuan (1980) do enraizamento como um vínculo não-consciente com um lugar tornou-se um dos pontos mais importantes e polêmicos nas discussões sobre o assunto em Psicologia Ambiental. Em suas palavras, "enraizamento é um estado de existência irrefletido no qual a personalidade humana funde-se com seu meio" (p. 6). Se objetivamente o enraizamento é caracterizado por longo tempo de habitação, subjetivamente é um estado ocasionado por "uma falta de curiosidade face ao mundo como um todo e uma falta de sensibilidade face ao fluxo do tempo" (p. 4). Tuan (1980) conclui:

Enraizamento em essência significa estar completamente em casa - isto é, irrefletidamente seguro e confortável em uma localidade particular. Exclui, assim, não apenas a ansiedade e a curiosidade pelo que existe além da próxima montanha, mas também pelo que existe além do tempo presente. (p. 5) 
O sentido de lugar, ao contrário, "implica certa distância entre o self e o lugar que permite ao self apreciar o lugar" (Tuan, 1980, p. 4). O sentido de lugar envolve, para o autor, consciência, ou uma relação refletida com o lugar.

Muitos autores partiram das definições de Tuan a fim de criticá-las. Hummon (1992, p. 262), por exemplo, define sentido de lugar como "as percepções subjetivas das pessoas sobre seus ambientes e seus sentimentos mais ou menos conscientes sobre eles" e defende, em oposição a Tuan, que algumas pessoas possuem um sentido de lugar enraizado, ou seja, caracterizado por um forte sentido de lar (Hummon, 1992, p. 263). Em seguida, defende que há dois tipos de enraizamento: o enraizamento cotidiano e o enraizamento ideológico. O que diferencia os dois tipos, fundamentalmente, é o grau de autoconsciência das pessoas sobre sua relação com a comunidade à qual se sentem enraizadas, maior no enraizamento ideológico (Hummon, 1992, p. 265). Hay (1998), seguindo Hummon (1992), também critica a separação estrita entre uma avaliação consciente e não consciente do ambiente, afirmando: "por meio de minha pesquisa empírica, tornou-se evidente que conceptualizações que separam o sentido de lugar e o enraizamento não eram sustentáveis" (Hay, 1998, p. 246). Ele argumenta que pessoas que se sentem incluídas em um lugar por nascimento ou longa permanência comumente adquirem posição social e um sentido de segurança. O grau de inclusão pode variar, sendo o mais profundo um tipo em que há uma associação sem autoconsciência, até mesmo subconsciente, com o lugar (p. 246). Entre os povos modernos, porém, o sentido de lugar perdeu esta conotação de profunda inclusão ou enraizamento e envolve mais uma apreciação estética (p. 246). Mesmo assim, ele defende a existência de um sentido de lugar enraizado, que pode ser aplicado a povos modernos ou indígenas com longa permanência como residentes, e que compreenderia as formas ideológica e cotidiana de enraizamento de Hummon (Hay, 1998, p. 246). De maneira geral, ele conclui, seguindo a ideia da recorrência dos ambientes vividos, que "desenvolver um sentido de lugar enraizado envolve longa residência, processo mais fácil quando a pessoa nasceu e cresceu no lugar" (p. 261). Além disso, a ênfase no aspecto espacial do enraizamento pode ser vista em afirmações como a de que "de modo geral, utilizar enraizado como descritor de 'sentido de lugar' ajuda a prover uma orientação que enfatiza o lugar mais que o sentido; assim, o termo torna-se mais geográfico que estético" (p. 263). Talvez haja aqui o pressuposto de uma temporalidade cíclica que, por não apresentar um claro sentido histórico de sucessão linear, destacaria a dimensão espacial na análise. Isto parece implícito na ideia de recorrência do ambiente vivido, mas raramente aparece articulado de maneira clara. É possível afirmar que para muitos autores, o sentido de lar e, por consequência, o de enraizamento, implicam recorrência, ou seja, predominância do passado sobre o presente e sobre o futuro, do já existente e conhecido sobre o novo e o desconhecido (Terkenli, 1995, p. 326).

Os aspectos identitários e psicossociais desta relação com o passado são também fundamentais para esta discussão. Algumas pesquisas em psicologia social revelaram que a experiência de um lar está intimamente relacionada à experiência de receptividade que cada pessoa pode viver em companhia de outros humanos. Sem esta experiência inicial de acolhimento pelos outros, dificilmente uma criança poderia experimentar sua própria casa como espaço de segurança e pertencimento (Gonçalves Filho, 1998b). Esse fato indica que a experiência da casa é também uma experiência simbólica que reflete as características do socioambiente familiar da criança. Psicólogos que estudaram o desenvolvimento infantil descreveram que a experiência positiva de lar deriva de um ambiente que seja percebido como seguro e estável, capaz de reconhecer a singularidade da criança (Winnicott, 2000). A experiência de um lugar como um lar deriva, portanto, de relações com outras pessoas nas quais essas experiências foram vividas e abrigadas em um determinado espaço, progredindo gradualmente para formas mais complexas de vínculo: "estar em casa é estar nos outros, é estar em si mesmo estando nos outros, falar da casa faz falar da casa nos outros" (Gonçalves Filho, 1998a, pp. 3-5). O entrelaçamento de tempo e espaço é fundamental nessa experiência: na casa humana, o tempo da convivência que apoia receptividade e acolhimento é também o espaço que simboliza vínculos anteriores e que se pretende manter ao longo de gerações. Dessa experiência hospitaleira inicial pode-se compreender sua derivação metafórica para a noção de comunidade como lar ampliado: a busca de um espaço público e coletivo que seja capaz de sustentar experiências de pertencimento, ou seja, formas de convivência que refletem segurança, respeito e participação pessoal.

\section{Enraizamento, Tempo e Identidade}

Pode-se argumentar que a metáfora da raiz, entendida como algo que sustenta e nutre um ser em 
crescimento, apoiou em grande medida a ideia de que o solo e os nutrientes estariam para a árvore na mesma relação que o passado e a biografia pessoal estariam para a identidade psicossocial. Mas neste caso, o desafio da psicologia ambiental está justamente em investigar a materialidade do passado e da história como alimento e fonte de sustentação na vida presente. O passado se materializa em signos, índices e sinais, que para se tornarem compreensíveis no presente, dependem constantemente de um campo de comunicação com outros humanos que ajudem a decifrar seu sentido. Este é o papel dos objetos biográficos e das memórias da família, como aponta Bosi (1994), é o papel das narrativas dos velhos na rememoração, dos professores no momento institucional da socialização, mas também é o papel do simples espaço cotidiano e familiar que vai sedimentando lembranças e que desejamos que permaneça inalterado como sinal de nosso lugar no mundo. A tensão entre a ênfase em um passado que sustenta a biografia e, portanto, a identidade, e a necessidade de integrar esta dimensão temporal a um socioambiente total que lhe dê sentido e no qual os diversos quadros temporais compareçam, em sua complexidade, para sustentar a possibilidade identitária, aparece em muitas obras dedicadas ao tema. Zimbardo e Boyd (1999), apesar de vincularem a ideia de raiz ao passado, defendem que sua importância reside, fundamentalmente, em contribuir para um "sentido de continuidade pessoal no tempo, alimentando assim uma perspectiva mais rica de futuro" (Zimbardo \& Boyd, 1999, p. 1285). Deve-se, portanto, fazer a crítica da ideia de que o enraizamento esteja sustentado essencialmente sobre um quadro temporal passado.

Tuan (2013), por exemplo, admite que não apenas o passado, mas o futuro, pode servir como quadro fundamental para a definição identitária. Esta possibilidade ele encontra, por exemplo, nos jovens, e afirma que "o que eles fazem, em vez do que eles possuem, define seu sentido de personalidade" (Tuan, 2013 , p. 229, grifos nossos). Grupos e indivíduos enraizados, ademais, não estão ocupados conscientemente com o passado - que surge como um aspecto integrado a sua vida cotidiana e sobre o qual eles não prestam atenção - porque, em princípio, isso não se mostra necessário: "O culto ao passado pouco tem a ver com o fato de se estar enraizado no lugar" (Tuan, 2013, p. 236). Quando um povo ou um indivíduo chega a ocupar-se conscientemente do passado, isso indica a necessidade correspondente de ocupar-se conscientemente de sua identidade, necessidade que surge quando a identidade é posta sob questão (Tuan, 2013, p. 238). Se considerarmos a relação já apontada entre a organização espacial e a orientação temporal objetiva, a criação de espaços que remetam enfaticamente ao passado e, portanto, pareçam indicar uma recorrência espacial conscientemente buscada, pode indicar a necessidade de reafirmar um sentido identitário no qual já não se pode confiar (Tuan, 2013, p. 239).

Pode-se então supor que haja certo deslocamento semântico no uso da palavra enraizamento, dependendo do contexto em que ela se encontra. Em alguns casos, a palavra é usada para referir-se à sustentação da identidade pessoal ou coletiva em quadros de referência sentidos como estáveis ou integrados à experiência e visão de mundo dos povos ou indivíduos (Broad \& Cavanagh, 2011). Em outros casos, para referir-se a um apego profundo por certas condições de vida, que chegam a bloquear e a impedir possibilidades vivenciais valiosas (McAndrew, 1998, p. 411). Terkenli (1995), por exemplo, afirma que pessoas enraizadas estão "restritas" e são "incapazes de associar-se a ambientes como lares além de seu ambiente imediato de vida e trabaIho" (Terkenli, 1995, p. 329). Giuliani (1991) também empresta ao termo um sentido de restrição e de perda ao afirmar que "a relação caracterizada pela preocupação com a preservação [de eventos irrepetíveis] é a que mais prontamente pode levar ao enraizamento" (Giuliani, 1991, p. 141).

Por outro lado, vemos também em Terkenli (1995, p. 331) uma reflexão sobre o quanto tal enraizamento restritivo pode estar implicado em um sentimento de perda de controle sobre o mundo e de ameaça à identidade. O autor afirma que isso ocorre, atualmente, num contexto no qual as conexões sociais cada vez mais intensas tendem a produzir profundas e rápidas mudanças geográficas, especialmente no sentido de "lar". A consequência é que as pessoas se aferram a uma ideia de lar muitas vezes irreal, e com mais intensidade quanto mais frágil é seu sentido. As mudanças no sentido de "lar" em um mundo globalizado podem ser tão intensas que restam poucas alternativas aos indivíduos para garantir alguma estabilidade a esta noção tão central à definição identitária. Em um caso extremo, a única saída é voltar-se para aquele contexto mais essencial da noção de lar, aquele que parece garantir um solo estável para esta noção por escapar às influências sociais que tornam todas as outras definições fluidas e incertas - o próprio eu (Terkenli, 1995, p. 332). 
A noção de "raiz" associada ao passado por Zimbardo e Boyd (1999) apresenta um sentido quase oposto a este último. Em um caso, um passado positivo é o alimento que permite sustentar presente e futuro, é um recurso do qual se pode fazer uso com alguma autonomia. Em outro, é a casamata para onde grupos e indivíduos dirigem-se a fim de se protegerem de um mundo percebido como ameaçador e fora de controle. Essa contradição mostra que discutir o enraizamento enfatizando um dos quadros temporais - o passado - como capaz de sustentar a identidade contradiz a maneira como as pessoas vinculam-se efetivamente aos seus socioambientes, articulando presente, passado e futuro de maneiras variáveis, e aponta para a necessidade de que a Psicologia Ambiental investigue quais condições sociais podem incentivar uma ou outra experiência de relação com o passado, e se seria mais rigoroso reservar a apenas uma delas a referência à experiência de enraizamento.

\section{Enraizamento como Horizonte Utópico}

Neste sentido, muitos autores indicam que as sociedades globalizadas ingressaram em uma era na qual a recorrência dos espaços vividos é cada vez mais incomum, e assim, tornaram-se raras as condições para o estabelecimento de relações enraizadas com o ambiente. Em seus extremos, as relações socioambientais daí derivadas podem ser caracterizadas como desenraizadas. Deve-se destacar esta característica semântica do termo enraizamento: de maneira semelhante à distinção estabelecida entre sociedade e comunidade por Tönnies (Miranda, 1995, p. 232), o oposto de enraizamento - o desenraizamento - indica uma condição indesejável. Por consequência, enraizamento implica uma condição desejável e que deve ser buscada. Esta característica distingue o enraizamento de qualquer outro termo correlato na Psicologia Ambiental, como apego ao lugar ou topofilia. Tais termos apresentam conotação analítica e podem ser considerados desejáveis ou indesejáveis a depender do contexto específico. Um prisioneiro, por exemplo, pode desenvolver apego ou identidade de lugar com a prisão, o que, para a sociedade como um todo, é altamente indesejável. Mas repugnaria dizer que um prisioneiro é um ser enraizado na prisão. Ao contrário, seria mais adequado dizer que a prisão desenraiza os prisioneiros frente à sociedade. Tuan (1980) inicia seu texto sobre enraizamento afirmando que, para o americano "moderno e autoconsciente", o enraizamento "é talvez um éden inalcançável" (p. 4). Weil (2001), por sua vez, afirma que "o enraizamento é talvez a necessidade mais importante e mais desconhecida da alma humana" (p. 43) e que "cada ser humano precisa ter múltiplas raízes" (p. 43). Os autores que discutem o tema do enraizamento não se atêm apenas a analisar as características das relações entre indivíduos, grupos e ambiente, mas adotam frequentemente um tom político e crítico da sociedade, o que também distingue este termo de outros correlatos neste campo do conhecimento. Em outras palavras, há um sentido utópico (Skinner, 2002) nas discussões sobre enraizamento e na crítica ao desenraizamento de indivíduos e grupos nas sociedades modernas.

Apfelbaum (2000), por exemplo, afirma que o desenraizamento "envolve a separação do indivíduo frequentemente irreversível, como nos casos de genocídio - de suas origens pessoais, sociais e históricas" (p. 1009). Weil (2001) caracteriza o desenraizamento como uma "doença" (p. 44, por exemplo), e afirma mesmo tratar-se, "de longe", da "doença mais perigosa das sociedades humanas" (p. 46). Desde a II Guerra Mundial, o tema do desenraizamento ganhou relevância em função dos eventos traumáticos vividos durante o período. Mas o aprofundamento dos processos sociais envolvidos com a globalização, especialmente nítidos a partir dos anos 1980, deram ao tema máxima relevância. Giddens (1991) atribui aos territórios sob o processo de globalização um caráter fantasmagórico, advindo de sua penetração por processos sociais distantes e desencaixados do lugar e lanni (1997) aponta o efeito desterritorializador da globalização sobre povos e indivíduos, que passam a caracterizar-se por um sentimento de alienação e perdimento que marcam a psicologia do homem moderno. Apfelbaum (2000) afirma com veemência que "da mesma forma que o final do século XIX foi rotulado de era das massas, o final do século XX será visto como a era do desenraizamento." (p. 1009). Alguns estudos sobre o desenraizamento o apontam como importante fonte de estresse e de adoecimentos na contemporaneidade, e indicam que este fenômeno deve ser levado em conta no planejamento de estratégias individuais e comunitárias para promoção de saúde (Coelho, Yuan, \& Ahmed, 1980).

A percepção de que o desenraizamento se aprofunda contemporaneamente deve-se em parte, mas não só, à intensa mobilidade que caracteriza as populações contemporâneas e impede que uma relação mais estável com o socioambiente se estabeleça, produzindo em indivíduos e grupos a percepção de perda de 
controle sobre o socioambiente. Hay (1998, p. 263), por exemplo, relaciona a mobilidade contínua à erosão do sentido de história, comunidade e lugar. Para McAndrew (1998, p. 410), o constante deslocamento espacial, especialmente involuntário, pode ameaçar a identidade pessoal e tornar-se esmagador para aqueles indivíduos com fortes ligações com o lugar. A recorrência dos ambientes vividos pode ser vinculada a uma percepção temporal direcionada ao passado e a constante mobilidade espacial pode parecer aos estudiosos como indicativa de um sistema social com direcionamento temporal voltado fundamentalmente ao futuro ou ao aprisionamento do tempo na repetição do presente.

Como observado por Hay (1998), porém, a experiência mais comum de desenraizamento não decorre da mobilidade voluntária, mas de rápidas e constantes mudanças promovidas no lugar de habitação por forças econômicas e sociais que aparecem aos olhos de indivíduos e grupos como incontroláveis. O mesmo pode ser observado quando ocorre a destruição de um lugar por ação humana ou causas naturais, ou o deslocamento forçado de populações por motivo de guerra, disputas econômicas, entre outros. Temos, nesses casos, o desenraizamento ocorrendo em sua forma mais aguda. O sentimento de desinteresse pela comunidade, comum em situação de constante mobilidade, dá lugar a uma clara percepção de perda e o sentimento resultante pode ser adequadamente descrito como luto (Hummon, 1992, p. 260).

Gostaríamos de sugerir que o campo semântico das noções de enraizamento e desenraizamento, em termos de suas conotações positiva e negativa, poderia ser proveitosamente mantido a fim de favorecer sua mais precisa conceituação. Além disso, seguindo a indicação de Altman e Rogoff (1991), gostaríamos de sugerir também que os elementos do socioambiente sejam tomados como "aspectos inseparáveis" do todo, ou seja, não sejam tomados isoladamente como indicativos de enraizamento ou desenraizamento. Ao contrário, que apenas em sua relação com a totalidade (Horkheimer, 1991) do socioambiente, tais elementos podem ser indicativos do grau de enraizamento de um indivíduo ou de um povo. Parece-nos interessante, também, apontar a centralidade do tema da identidade, seja psicossocial, seja coletiva, como distintiva das discussões a respeito da noção de enraizamento. Além disso, consideramos importante enfatizar como este tema, no campo da Psicologia Ambiental, esteve sempre relacionado ao da temporalidade e ao da perspectiva temporal.

\section{Enraizamento e participação: Algumas conclusões sobre a articulação entre as dimensões temporais e espaciais do socioambiente}

É uma afirmação autoevidente, mas que merece ser enfatizada, a de que uma relação "balanceada" entre perspectivas temporais não pode advir simplesmente da recorrência de um ambiente. Assim, definir enraizamento objetivamente como habitação por longo tempo em uma localidade (Schellenberg et al., 2018) - na forma que Terkenli (1995, p. 330) atribui a Tuan diz pouco sobre o próprio fenômeno e sobre as razões pelas quais ele pode se tornar objeto de desejabilidade. Se levarmos a fundo a crítica ao determinismo ambiental realizado pela psicologia ambiental, devemos admitir que o indivíduo não está inerte face ao mundo ao redor, não se encontra em posição passiva, e que sua atividade é tão determinante quanto os ambientes objetivos nos quais se encontra. A atividade individual e coletiva não apenas transforma o ambiente, mas, dialeticamente, ao fazê-lo, cria formas específicas pelas quais o ambiente é apropriado. Um dos aspectos desta apropriação tem relação com as perspectivas temporais e com a orientação temporal do próprio ambiente, de modo que "toda atividade gera uma estrutura espaço-temporal especial" (Tuan, 2013, p. 161). Hummon (1992) parece indicá-lo ao afirmar que o sentimento de comunidade tem origens complexas "nos aspectos objetivos e subjetivos do ambiente local" (Hummon, 1992, p. 253) e ao afirmar que o ambiente pode ser não a causa, mas a consequência da ação individual e coletiva. Lipman e Harris (1980) são enfáticos ao afirmar que ambientes construídos não são meros containers da ação social, mas que incorporam significados construídos socialmente e que, neste sentido, são reconstruções do mundo físico que entram em orquestração com códigos espaciais culturalmente constituídos.

Mas a forma como se dá esta relação entre ação, ambiente e perspectiva temporal não é, tampouco, neutra. Ao contrário, nem toda forma de orientação temporal é sentida como adequada por indivíduos e coletividades e nem toda constituição ambiental é vista como desejável. Se a discussão sobre enraizamento nos mostra algo, é que certas relações entre ambiente 
e identidade podem ser nocivas para indivíduos e coletividades e podem levar à destruição de vínculos sentidos como fundamentais para a definição identitária. Kurt Lewin (1970) observou que se a atividade lúdica de uma criança sofrer interferência, seu nível de produtividade poderá regredir devido à perturbação em sua perspectiva temporal, marcada agora por um "background de insegurança e frustração" que "reduz a iniciativa" (Lewin, 1970, p. 127). A ênfase no passado aqui, um passado que gera insegurança, não pode ser analiticamente cindida de uma percepção de futuro incerto e ameaçador. O fundamental neste caso não é tanto a orientação predominante, mas o fato de que a conjugação entre ambiente inseguro e uma específica orientação temporal para o passado, na qual o futuro parece imprevisível, relaciona-se com uma percepção individual de ausência de controle. Neste caso, em um ambiente autocrático, o indivíduo torna-se incapaz de perceber relações entre suas ações e a constituição do ambiente realmente existente e sente-o como opressivo e sufocante.

A situação total, incluindo temporalidade objetiva, perspectiva temporal, ação individual e ação coletiva, pode configurar-se de tal forma que a aparição individual seja experimentada como reificada ou seja, as possibilidades de expressão pessoal ficam dificultadas ou congeladas em função da desigualdade política presente em certo campo de convivência (Gonçalves Filho, 1998b). O argumento crítico de Tuan (2013) a respeito da ênfase no passado ganha sentido quando pensamos sobre a relação entre ação e identidade. O passado idealizado e aprisionador não é decorrência direta de um ambiente em transformação acelerada, mas de um ambiente no qual tal transformação é sentida como opressiva e incontrolável: "sempre que uma pessoa (jovem ou velha) sente que o mundo está mudando muito rapidamente, sua resposta característica é evocar um passado idealizado e estável" (Tuan, 2013, p. 229), mas quando ela sente que "está dirigindo as mudanças, então a saudade não tem lugar em sua vida: a ação, em vez de lembranças do passado, apoiará seu sentido de identidade" (p. 229). Uma orientação temporal voltada para um passado aprisionador, assim, parece ser mais decorrência da percepção de ausência de controle do que do grau em que um ambiente muda ou permanece estável.

Se a ação do indivíduo e do grupo é parte fundamental da estrutura espaço-temporal, tal estrutura pode promover uma desorganização da identidade psicossocial e coletiva ou, ao contrário, permitir que esta identidade esteja ancorada em um passado que a alimenta, em um presente que se abre em caminhos sobre os quais pode deliberar, e em um futuro que sente como produto de suas decisões individuais e coletivas. Gostaríamos de defender, seguindo Lewin (1970, p.128), que apenas neste último sentido a ação pode ser chamada rigorosamente de participação. Considerando-se democracia como o regime no qual as identidades psicossociais podem expressar-se autonomamente em uma coletividade, definindo, pela sua ação livre, os rumos desta coletividade, Lewin (1970, p.132) considera que apenas nesta situação a perspectiva temporal tende a manter altos o moral e a produtividade de um grupo: "No grupo democrático, a 'aceitação' do objetivo grupal pelo membro significa que este o compreende e o faz seu" (Lewin, 1970, p. 133).

A participação que permite ao indivíduo sentir-se responsável pelo futuro de sua coletividade e, ao mesmo tempo, herdeiro de um passado comum, o qual engloba a memória coletiva, a cultura e o lugar, é relacionada por alguns autores a formas de enraizamento que fomentam o crescimento pessoal e coletivo. Terkenli (1995) afirma que uma percepção de passado e de futuro que fomente crescimento é componente essencial do enraizamento e do sentido de casa: "o enraizamento carrega o potencial de ampliar o ser pessoal ao tornar os indivíduos cônscios de sua própria identidade e das possibilidades que surgem ao estender suas circunstâncias de vida ao passado e ao futuro" (Terkenli, 1995, p. 330). Hummon (1992) identifica este tipo de relação com o que ele chama de enraizamento ideológico e afirma: "no enraizamento ideológico, sentimentos fortes de satisfação, apego e lar são combinados com uma identificação autoconsciente com a comunidade" (Hummon, 1992, p. 264). Seguindo Giuliani (1991, p. 141), pode-se afirmar também que o sentimento de estar em casa, conquanto dependa de permanência no lugar e familiaridade, depende ainda mais da percepção de que o lugar é "seu" no sentido de que o indivíduo e o grupo, de forma livre, são responsáveis pela sua existência. Simone Weil define enraizamento desta forma: "Um ser humano tem raiz por sua participação real, ativa e natural na existência de uma coletividade que conserva vivos certos tesouros do passado e certos pressentimentos do futuro" (Weil, 2001, p. 43). Participação natural, a autora define como "aquela ocasionada automaticamente pelo lugar, nascimento, profissão, meio" (Weil, 2001, p. 43, grifos nossos). Raiz 
não é, portanto, uma decorrência do passado, mas uma relação específica entre passado, presente e futuro, entre indivíduo e socioambiente como um todo, pela qual o indivíduo percebe sua existência na coletividade e no próprio socioambiente como marcada por sua capacidade de expressar-se livremente e determinar, por meio de sua ação em coletividade, os caminhos de seu grupo ou de seu povo; em que, em suma, sente-se capaz de participar.

Como conclusão, gostaríamos de sugerir que o termo enraizamento seja referido, de modo geral, à relação intrínseca entre a formação da identidade psicossocial e o socioambiente, em sentido amplo, no qual se constitui tal identidade. O termo socioambiente, na forma como é utilizado nas discussões sobre enraizamento, deve ser entendido em sentido suficientemente amplo para abranger a cultura de um povo, sua história e organização política, sua memória coletiva, entre outros elementos. A partir de então, campo socioambiental passa a significar o entrelaçamento das dimensões do espaço e do tempo, pois ambas constituem aspectos de uma unidade fenomênica. Weil (2001) afirmou que a construção do futuro depende do alimento trazido pelo passado, mas um passado digerido e relacionado às questões do presente. $A$ identidade que a raiz apoia, floresce e dá seus frutos apenas em um campo aberto de comunicação e participação, única possibilidade de que esse vínculo não se torne repetição rígida, mas efetiva assimilação e elaboração que sustenta uma aparição singular. A noção de identidade passa a se relacionar intimamente com as possibilidades de participação abertas pelo campo social. A abertura e o entrelaçamento das experiências temporais dependem do tipo de comunicação, do trabalho realizado e das estruturas de poder nos espaços vividos pelos sujeitos. A participação pode ser considerada uma forma de abertura da existência individual em direção ao futuro estabelecida coletivamente num campo de cooperação definido. O espaço social é produzido, portanto ele é símbolo desta articulação e remete continuamente à história das atividades econômicas e das formas de convivência política. Caso as pessoas vivam uma configuração social que é afirmação repetida e constrangedora de um passado mítico e intocado, sem a abertura de espaços no presente para assimilação e participação nos rumos do grupo, o enraizamento é assim tensionado à repetição. Quando o presente é mera repetição de si mesmo, sem ligação com as esperanças e os "tesouros do passado" e sem projetos efetivos de futuro, configura-se uma situação de dominação que pode ser traduzida pessoalmente como desconforto ou angústia. A partir deste ponto, qualquer análise ambiental está apta a considerar as estruturas de poder a qual as pessoas estão submetidas, que reproduzem ou que alteram, e isto porque o espaço e o tempo passam efetivamente a simbolizar estas estruturas, são ocasiões e apoio para uma distensão ou contração do tempo pessoal e coletivo.

\section{Referências}

Altman, I., \& Rogoff, B. (1991). World views in psychology: Trait, interactional, organismic and transactional perspectives. In D. D. Stokols \& I. Altman (Orgs.), Handbook of environmental psychology (pp. 7-40). Nova lorque: Wiley.

Apfelbaum, E. (2000). And now what, after such tribulations? Memory and dislocation in the Era of Uprooting. American Psychologist, 55(9), 1008-1013. doi: 10.1037/0003-066X.55.9.1008

Bosi, E. (1994). Memoria e sociedade: Lembrancas de velhos (3a․ ed). São Paulo: Companhia das Letras.

Broad, R., \& Cavanagh, J. (2011). Reframing development in the age of vulnerability: from case studies of the Philippines and Trinidad to new measures of rootedness. Third World Quarterly, 32(6), 1127-1145. doi: 10.1080/01436597.2011.586232

Bronfenbrenner, U., \& Morris, P. A. (2006). The bioecological model of human development. In W. Damon \& R. M. Lerner (Orgs.), Handbook of child psychology: Vol. 1. Theoretical models of human development (6 $6^{\underline{a}}$ ed., pp. 793-828). Nova York: John Wiley \& Sons.

Canter, D. V., \& Craik, K. H. (1981). Environmental psychology. Journal of Environmental Psychology, 1(1), 1-11. doi: 10.1016/ S0272-4944(81)80013-8

Cavalcanti, S., \& Elali, G. A. (2011). Apresentação. In S. Cavalcanti \& G. A. Elali, (Orgs.), Temas básicos em Psicologia Ambiental (pp. 11-20). Petrópolis, RJ: Vozes.

Coelho, G. V., Yuan, Y. T., \& Ahmed, P. (1980). Contemporary uprootings and collaborative coping: Behavioral and societal responses. In G.V. Coelho \& P. Ahmed (Orgs.), Uprooting and development. (pp. 5-17). Nova lorque e Londres: Plenum Press.

Corral-Verdugo, V., Fraijo-Sing, B., \& Pinheiro, J. Q. (2006) Sustainable behavior and time perspective: Present, past, and future orientations and their relationship with water conservation behavior. Interamerican Journal of Psychology, 40(2), 139-147. Recuperado de http://pepsic.bvsalud.org/scielo. php?script=sci_arttext\&pid=S0034-96902006000200001\&lng=pt\&ting=en

Farias, T. M. (2017). Afetividade e resistência: vínculo, transformações socioambientais e oposição capital-lugar na cidade de Galinhos- $R N$ (Tese de doutorado). Recuperado de https://repositorio.ufrn.br/jspui/ handle/123456789/24345

Frank, L. K. (1939). Time perspectives. Journal of Social Philosophy, 4, 293-312.

Giddens, A. (1991). As consequências da modernidade (5 $5^{\underline{a}}$ ed.). São Paulo: UNESP.

Gifford, R. (2014). Environmental Psychology Matters. Annual Review of Psychology, 65(1), 541-579. doi: 10.1146/ annurev-psych-010213-115048 
Giuliani, M. V. (1991). Towards an analysis of mental representations of attachment to the home. Journal of Architectural and Planning Research, 8, 133-146.

Gonçalves Filho, J. M. (1998a). A memória na casa e a memória dos outros. Travessia - Revista do Migrante, 9(32).

Gonçalves Filho, J. M. (1998b). Humilhação social: um problema político em psicologia. Psicologia USP, 9(2), 11-67. doi: 10.1590/ S0103-65641998000200002

Hay, R. (1998). A rooted sense of place in cross-cultural perspective. Canadian Geographer / Le Géographe Canadien, 42(3), 245-266. doi: 10.1111/j.1541-0064.1998.tb01894.x

Horkheimer, M. (1991). Teoria tradicional e teoria crítica. In Z. Loparic, A. M. Lorapic, E. A. Malagodi, R. P. Cunha, L. J. Baraúna, \& W. L. Maar (Orgs.), Textos escolhidos (5 $5^{\underline{a}}$ ed., pp. 31-68). São Paulo: Nova Cultural.

Horkheimer, M., \& Adorno, T. W. (1973). Ideologia. In M. Horkheimer \& T. W. Adorno (Orgs.), Temas básicos de sociologia (pp. 184-205). São Paulo: Cultrix; Editora da Universidade de São Paulo.

Hummon, D. M. (1992). Community attachment. Local sentiment and sense of place. In I. Altman \& S. M. Low (Orgs.), Place attachment (pp. 253-278). Nova lorque: Plenum Press.

lanni, O. (1997). A sociedade global (5ª ed.). Rio de Janeiro: Civilização Brasileira.

Lewicka, M. (2010). Place attachment: How far have we come in the last 40 years? Journal of Environmental Psychology, 31(3), 207-230. doi: 10.1016/j.jenvp.2010.10.001

Lewin, K. (1970). Moral e perspectiva temporal. In G. W. Lewin (Org.), Problemas de dinâmica de grupo (pp. 119-140). São Paulo: Cultrix.

Lewin, K. (1973). Princípios de Psicologia Topológica. São Paulo: Cultrix.

Lewin, K. (1989). Problemas de dinâmica de grupo (4⿳亠丷厂 ed.). São Paulo: Cultrix.

Lipman, A., \& Harris, H. (1980). Environmental Psychology - a sterile research enterprise? Built Environment, 6(1), 68-74. Recuperado de http://www.jstor.org/stable/23286087

Massola, G. M., Crochík, J. L., \& Svartman, B. P. (2016). A psicologia como ciência empírica. Psicologia USP, 27(3), 379-394. doi: 10.1590/0103-656420162703

McAndrew, F. T. (1998). The measurement of "rootedness" and the prediction of attachment to home-towns in college students. Journal of Environmental Psychology, 18(4), 409-417. doi: 10.1006/ jevp.1998.0078

Melo, R.G.C.(1991).Psicologiaambiental:umanovaabordagemdapsicologia. Psicologia USP, 2(1-2), 85-103. Recuperado de http://pepsic.bvsalud. org/scielo.php?script=sci_arttext\&pid=S1678-51771991000100008\&lng= pt\&ting=pt
Milfont, T. L., \& Demarque, C. (2015). Understanding environmental issues with temporal lenses: Issues of temporality and individual differences. In M. Stolarski, N. Fieulaine, \& W. van Beek (Orgs.), Time perspective theory; review, research and application (pp. 371-383). Nova lorque, Londres: Springer International Publishing. doi: 10.1007/978-3-319-07368-2

Miranda, O. (Org.). (1995). Para ler Ferdinan Tönnies. São Paulo: EDUSP.

Philip, D. (1996). The practical failure of architectural Psychology. Journal of Environmental Psychology, 16(3), 277-284. doi: 10.1006/ jevp. 1996.0023

Pinheiro, J. Q. (2013). Time, a slippery challenge. IAPS - Bulletin, 39 , 8-13. Recuperado de https://issuu.com/iaps-association/docs/ iaps_bulletin_39_issuu

Pinheiro, J. Q., \& Gurgel, F. F. (2011). Perspectiva temporal. In S. Cavalcant \& G. A. Elali (Orgs.), Temas básicos em Psicologia Ambiental (pp. 267-280). Petrópolis: Vozes.

Saegert, S., \& Winkel, G. H. (1990). Environmental Psychology. Annual Review of Psychology, 41(1), 441-477. doi: 10.1146/annurev. ps.41.020190.002301

Schellenberg, G., Lu, C., Schimmele, C., \& Hou, F. (2018). The correlates of self-assessed community belonging in Canada: Social capital, neighbourhood characteristics, and rootedness. Social Indicators Research, 140(2), 597-618. doi: 10.1007/s11205-017-1783-1.

Skinner, Q. (2002). The foundations of modern political thought (11 $\stackrel{\text { a }}{\mathrm{ed}}$.) Cambridge: Cambridge University Press.

Tassara, E.T. O. (2006). O pensamento contemporâneo e o enfrentamento da crise ambiental: uma análise desde a Psicologia Social. In I. C. M. Carvalho, M. Grün, \& R. Trajber (Orgs.), Pensar o ambiente: bases filosóficas para a educação ambiental (pp. 221-233). Brasília: Ministério da Educação, Secretaria de Educação Continuada, Alfabetização e Diversidade, UNESCO.

Terkenli, T. S. (1995). Home as a Region. Geographical Review, 85(3), 324-334. Recuperado de http://www.jstor.org/stable/215276

Tuan, Y.-F. (1980). Rootedness versus Sense of Place. Landscape, 24, 3-8.

Tuan, Y.-F. (2013). Espaço e lugar. A perspectiva da experiência. Londrina: Eduel.

Weil, S. (2001). O enraizamento. Bauru: Editora da Universidade do Sagrado Coração.

Winnicott, D. W. (2000). Da pediatria à psicanálise: obras escolhidas. Rio de Janeiro: Imago.

Zimbardo, P. G., \& Boyd, J. N. (1999). Putting time in perspective: A valid, reliable individual-differences metric. Journal of Personality and Social Psychology, 77(6), 1271-1288. doi: 10.1037/0022-3514.77.6.1271

Zimbardo, P. G., \& Boyd, J. N. (2008). The time paradox: understanding and using the revolutionary new science of time. Nova lorque: Free Press.

1. Este trabalho recebeu apoio da Fundação de Amparo à Pesquisa do Estado de São Paulo (FAPESP), processo n. 2018/00728-8.

2. Como exemplos, citamos as dificuldades de se compreender as relações entre a percepção subjetiva do tempo e o tempo cosmológico (que se inscreve nas variadas formas culturais dos calendários), e a relação entre percepção do tempo e variação espacial dos corpos e objetos. 
Gustavo Martineli Massola, Doutor em Psicologia Social pela Universidade de São Paulo (USP), é Professor Assistente na Universidade de São Paulo (USP). Endereço para correspondência: Rua Silverstone, 134, Residencial San Diego, Vargem Grande Paulista (SP), CEP 06.730-000. E-mail: gustavomassola@usp.br

Bernardo Parodi Svartman, Doutor em Psicologia Social pela Universidade de São Paulo (USP), é Professor Assistente

na Universidade de São Paulo (USP).

E-mail:bernardo@usp.br

Recebido em 30.Jan.18

Revisado em 07.Dez.18

Aceito em 22.Mar.19 